\title{
Genetic disease and amyloid
}

\author{
J. R. HOBBS
}

\section{From the Westminster Hospital Medical School, London}

Amyloid results from the deposition, principally in connective tissue, of polymers that are for the most part incompletely digested precursor proteins. In man the resulting deposits are very resistant to resorption or digestion: their relentless accumulation often causes death by interfering with the function of vital organs such as the kidneys, heart, and gut.

There are three definitive methods for recognising amyloid. (1) The dye congo red is bound more strongly by amyloid than by human albumin (Bennhold, 1922). It then exhibits a green birefringence in polarised light (Missmahl, 1957). (2) Electron microscopy reveals a characteristic fibrillar structure (Cohen and Calkins, 1959) that is nonbranching, of variable length, and 8-15 nm wide. (3) $X$-ray diffraction shows a pattern with an outer band of $4.75 \AA$ and an inner band of $9.8 \AA$ (Eanes and Glenner, 1968).

These three properties result from an antiparallel $\beta$-pleated sheet conformation with the grooves of the pleats running along the length of the fibril. The bends of the pleating probably coincide with glycine or proline residues at about every 16 amino-acids. It is these amino-acids that seem to make amyloid fibrils very resistant to digestion. Only enzymes such as pronase can disrupt the $\beta$ pleated sheet conformation, simultaneously destroying the three characteristic properties. The most sensitive method for detecting early amyloid deposition in tissues is electron microscopy. For preliminary screening, however, fluorescence microscopy after staining with thioflavine-T (Vassar and Culling, 1959), while not entirely specific, rarely fails to identify true amyloid (Hobbs, 1973).

The genetic varieties of amyloidosis are rare in Britain. When all parts of the world are considered, however, some 2000 patients are now recorded. In most cases this relentless disease results from the overproduction of the amyloid precursor proteins. Symptoms appear between $25-45$ years of age. The clinical disorder progresses to death within 10 years. An elegant description of most of the genetic varieties of amyloid has been written by Cohen (1972), and a simplified form of his clinical classification is used in this brief report. It is emphasised that many classifications of amyloid (Hobbs, 1973) have not yet benefited from the new knowledge gained about the precursor proteins; all classifications overlap. It is nevertheless reasonable to review the main genetic forms of amyloid in terms of the clinical character of their onset. I then consider how the excess of amyloid precursors occurs. Surely this must offer a key to the best hope for managing these diseases.

\section{Clinical onset}

The predominant clinical presentations of genetic amyloid may be classified as (1) neuropathic, (2) nephropathic, (3) cardiopathic, and (4) miscellaneous.

So far as is known, all the genetic forms of amyloid except familial Mediterranean fever, which is inherited as an autosomal recessive characteristic, have a Mendelian autosomal dominant inheritance.

\section{NEUROPATHIC FORMS}

The neuropathic forms are classified as (1) lower limb, associated with vitreous opacities but not the carpal tunnel syndrome (Portuguese type); (2) upper limb, with vitreous opacities and carpal tunnel syndrome (Swiss-German types); (3) all limbs plus kidney but without vitreous opacities or carpal tunnel syndrome.

Andrade (1952) first drew attention to the heredo-familial forms of amyloid when he described the so-called Portuguese type. This has now been recorded in all parts of the world. The distribution recalls the historic travels of Portuguese sailors (Cohen, 1972). The major difference between the Portuguese and the Swiss-German types is the rarity in the former of the carpal tunnel syndrome. This suggests either a difference in the affinity of the precursor proteins for carpal tunnel collagen or a difference in the carpal tunnel collagen between Portuguese-descended and Swiss-German subjects. Both forms often develop cardiac complications, probably due to involvement of the innervation of the heart. The third variety overlaps with the nephropathic group.

In all three forms and associated varieties (Cohen, 1972) a careful study of the distribution of the amyloid suggests that collagen is one of the main connective tissue components to which amyloid fibrils become bound. The major mechanism for 
damage to the nerves seems to be by interference with vasa nervorum. Indeed, even when the pericollagenous amyloid compresses the carpal tunnel it is probably a vascular mechanism that injures nerves.

\section{NEPHROPATHIC FORMS}

The nephropathic forms are (1) autosomal recessivefamilial Mediterranean fever (FMF); and (2) autosomal dominant-Swedish; Sicilian; with urticaria and deafness; with hypertension.

FMF was recognised in 1945. It is particularly prevalent among the non-Ashkenazim (Sephardic) Jews (Sheba, 1970) and Armenians, yet also occurs in Arabs and Turks and is world-wide. It was not till some years after Andrade's work that it was realised that amyloid develops in more than half the patients. Their periodic fever is often associated with polyserositis and neutrophilia. These periodic bouts are unrelated to the serum concentrations of steroids such as aetiocholanolone. In the affected population the homozygotes occur with a frequency of about 1 in 2000, suggesting that the heterozygotes occur with a frequency of 1 in 45 . By measuring the serum levels of precursor proteins it has been possible to recognise those forms of leprosy which result in amyloid (McAdam et al., 1975); a similar approach might detect FMF heterozygotes to enable genetic counselling. With such a high gene frequency recognition could prove a great blessing.

Because of the relentless nature of the disease there has been much research into its mechanisms. It was the first disease in which the AA form of amyloid protein was identified (Benditt et al., 1962; Pras and Reshef, 1972) and sequenced (Levin et al., 1972). Subsequently it became clear that the AA protein was identical with that found in the commoner amyloid that is secondary to many forms of chronic inflammation. Since the amino-acid sequences are virtually identical it follows that the affinity of the polymerised molecules for connective tissue components such as reticulin fibrils is similar in all such conditions. This may account for the 'typical' distribution of amyloid. Renal failure is the most common cause of death. It is not yet clear whether the patients produce an excess of amyloid precursor proteins because of an underlying predilection to inflammation, or whether the phagocytes of affected patients produce more precursors for a given degree of inflammation. Studies of these mechanisms have not yet been made in the dominant forms of nephropathic amyloid. Unusual symptomatology, such as urticaria and deafness (Muckle and Wells, 1962), suggests either that there is a change in the affinity of precursor proteins or an alteration in the receptivity of the connective tissues of the skin and ear.

\section{CARDIOPATHIC FORM}

The cardiopathic form is of two types-the Scandinavian and the Latin-American.

First described in Denmark (Frederiksen et al., 1962), this genetic form has a pericollagen-type deposition, particularly beneath the limiting membrane of the myocardial syncitium. The cells thus become encased in a rigid coat of amyloid; impaired diastolic filling is characteristic. An almost identical form of amyloid is sometimes seen in patients with myelomatosis, but no immunoglobulin monoclonal components have been identified in this genetic variety. While it is suggested that the amyloid is primarily deposited in the heart, there is a paucity of complete necropsy information. The same may be said of the Latin-American variety, the clinical features of which are typified by atrial standstill.

\section{MISCELLANEOUS FORMS}

The miscellaneous forms are (1) systemic, secondary to genetic immune deficiency; and (2) localised(a) lattice corneal dystrophy, (b) skin, and (c) tumourproduced (familial endocrine-neoplasia type II).

The amyloid which can complicate agammaglobulinaemia is 'typical' in perireticulin distribution and almost certainly of AA type. Why the skin (Isaak, 1965) or the cornea (Klintworth, 1967) should be preferential sites for deposition is unknown. However, it was logical to speculate (Hobbs, 1973) that the amyloid deposited locally in relation to tumours of the APUD (amine-precursor-uptake-decarboxylation) system (Pearse, 1969) would be proved to be due to the polymerisation of homogeneous, low molecular-weight products of such cell lines. It is therefore interesting to find that analysis of the amyloid deposited with medullary carcinoma of the thyroid (Williams et al., 1966) has shown identity with thyrocalcitonin (Tashjian et al., 1974; Sletten et al., 1976). Furthermore, it seems likely that degraded insulin can produce amyloid-like material (Glenner et al., 1974).

The amyloid fibrils represent about $90 \%$ of the amyloid deposition, but other proteins can be trapped. These may include glycoproteins as well as the P-component (protein AP may be found in identical form in normal serum as a subcomponent of the $\mathrm{Cl}$ fraction of complement and has been called C1t (Pepys et al., 1977). The significance of these minor components is largely unknown.

In the commonest forms of amyloid, that secondary to chronic inflammation (AA) and that secondary to B-lymphocyte neoplasia (light chain), the amyloid fibrils are polymers of homogeneous 
proteins. Since the AA proteins isolated from a large variety of diseases as well as FMF have an identical amino-acid sequence they could be expected to form very similar polymers and have identical affinities for connective tissues, thus explaining the 'typical' perireticulin distribution of such amyloid. The normal polyclonal mixture of light chains cannot polymerise. Only the abnormal monoclonal light chains secreted by B-lymphocyte neoplasms (Hobbs, 1973) can polymerise and sometimes give rise to amyloid. These light chains probably undergo preliminary digestion before being formed into amyloid fibrils; only about $30 \%$ of monoclonal light chains are likely to be able to form amyloid.

The part of the light chain most resistant to partial digestion is the variable portion which, of course, can participate in about $25 \%$ of the binding affinity of the antigen-binding site of the complete immunoglobulin molecule. Because of the wide variability among such monoclones a wide variation in binding affinity can be assumed. This may explain the 'atypical' affinity of amyloid secondary to myelomatosis; it is mostly pericollagen but sometimes perireticulin. Osserman et al. (1964) first realised that the binding affinity of the circulating light chains probably determined the distribution of consequential amyloid. This experience, applied to the consideration of the genetic varieties of amyloidosis, should teach us to search for precursor proteins with affinity for particular affected tissues in order to account for the patterns of disease. As yet only FMF and thyrocalcitonin amyloid have been identified.

Probably the neuropathic and cardiopathic pericollagen amyloids will be shown to be results of precursors that resemble the monoclonal variants of light chains more closely than AA protein. I have been unable to find material resembling Bence Jones protein in urine concentrated 300 times collected from patients with the Portuguese neuropathy, the Scandinavian cardiopathy, or FMF. In such patients, therefore, the precursor possibly circulates in a polymerised form not readily excreted in the urine. This seems to be the case for AA amyloid, of which the precursor protein, known as SAA, has a molecular weight of $80-90000$ daltons as against 7000 daltons for the AA protein itself.

Serum concentrations of SAA vary greatly in the normal population, both with age and with episodes of inflammation. At first it was thought they would not be helpful guides in predicting the development of amyloid. However, McAdam et al. (1975) observed that certain forms of leprosy were more likely to be followed by amyloid than others. Susceptible patients had the highest neutrophil counts during their episodes of fever. Probably a similar phenomenon occurs in FMF, and SAA is now believed to be a product of the phagocytes provoked by the inflammatory process. Indeed, some human subjects may produce higher levels of SAA than others for the same degree of neutrophilia. This response could be due to a relative increase in production or a relative decrease in the loss of the precursor. Either could result in further degradation of SAA to form the low molecular weight AA components that can polymerise to form amyloid.

Recognition that SAA levels were related to neutrophilia in patients developing amyloid stimulated trials of colchichine prophylaxis when it was thought that amyloid was of AA type, as is usual in the systemic connective tissue diseases. Several investigations are in progress (Lancet, 1977), and Levy and Eliakim (1977) report good responses in FMF with little toxicity over a four-year period of observation. There has been no measurement of the degree of amyloidosis before and after therapy in these cases and no untreated controls have been compared with treated patients. The preliminary data nevertheless justify the need for formal trials. There is now growing evidence that arresting the production of precursors such as Bence Jones protein by giving cytotoxic drugs will lead to slow resorption of amyloid (Jones et al., 1972). The patient reported in 1972 had improved even further in 1977 although amyloid fibrils still persisted in a renal biopsy in that year. Since then $I$ have encountered three similar cases. There are other reports, supported by biopsy evidence, before and after treatment. This is in sharp contrast to welladvanced amyloid in which genuine resorption is unusual although progression can sometimes be arrested.

\section{Conclusion}

The terrible fate that awaits patients cursed with these genetic forms of amyloid demands continued effort to try to identify the proteins of the various amyloid fibrils. The precursor proteins circulating in most patients with the systemic forms of the disease must also be identified. Searches must be made for subtle variations in the production of near-normal or normal precursors and for the removal or degradation of such substances. There may be variations in the affinity of these substances or in the receptivity for them of the tissues of the gentically affected patient. Most forms of genetic amyloid do not present clinically until after the age of 25 years. Certain identification of precursors would therefore be needed to permit prophylactic eugenics in the dominant forms of these diseases. Paradoxically, excessive production of SAA may first be detected in 
the recessive form, FMF. Clear distinction between the clinical patterns indicates that there are different precursor proteins in different genetic varieties of amyloid. A rich harvest awaits the enthusiastic investigator.

\section{References}

Andrade, C. (1952). A peculiar form of peripheral neuropathy: familial atypical generalised amyloidosis with special involvement of the peripheral nerves. Brain, 75, 408-427.

Benditt, E. P., Lagunoff, D., Eriksen, N., and Iser, O. A. (1962). Amyloid. Extraction and preliminary characterisation of some proteins. Archives of Pathology, 74, 323-330.

Bennhold, H. (1922). Eine spezifische Amyloidfärbung mit Kongorot. Münchener medizinische Wochenschrift, 69, 1537-1538.

Cohen, A. S. (1972). Inherited systemic amyloidosis. In The Metabolic Basis of Inherited Disease, edited by J. B. Stanbury, J. B. Wyngaarden, and D. S. Fredrickson, 3rd edition, pp. 1273-1294. McGraw-Hill, New York.

Cohen, A. S., and Calkins, E. (1959). Electron microscopic observations on a fibrous component in amyloid of diverse origins. Nature (London), 183, 1202-1203.

Eanes, E. D., and Glenner, G. G. (1968). $X$-ray diffraction studies of amyloid filaments. Journal of Histochemistry and Cytochemistry, 16, 673-677.

Frederiksen, T., Gotzsche, H., Harboe, N., Kiaer, W., and Mellemgaard, K. (1962). Familial primary amyloidosis with severe amyloid heart disease. American Journal of Medicine, 33, 328-348.

Glenner, G. G., Eanes, E. D., Bladen, H. A., Linke, R. P. and Termine, J. D. (1974). $\beta$-pleated sheet fibrils; a comparison of native amyloid with synthetic protein fibrils. Journal of Histochemistry and Cytochemistry, 22, 1141-1158.

Hobbs, J. R. (1973). An A B C of amyloid. Proceedings of the Royal Society of Medicine, 66, 705-710.

Isaak, L. (1965). Localised amyloidosis cutis associated with psoriasis in siblings. Archives of Dermatology and Syphilology, 61, 859-862.

Jones, N. F., Hilton, P. J., Tighe, J. R., and Hobbs, J. R. (1972). Treatment of 'primary' renal amyloidosis with Melphalan. Lancet, 2, 616-619.

Klintworth, G. K. (1967). Lattice corneal dystrophy: an inherited variety of amyloidosis restricted to the cornea. American Journal of Pathology, 50, 371-400.

Lancet (1977). Colchicine in familial Mediterranean fever. Leading article. Lancet, 1, 1140-1141.
Levin, M., Franklin, E. C., Frangione, B., and Pras, M. (1972). The amino acid sequence of a major nonimmunoglobulin component of some amyloid fibrils. Journal of Clinical Investigation, 51, 2773-2776.

Levy, M., and Eliakim, M. (1977). Long-term colchicine prophylaxis in familial Mediterranean fever. British Medical Journal, 2, 808.

McAdam, K. P. W. J., Anders, R. F., Smith, S. R., Russell, D. A., and Price, M. A. (1975). Association of amyloidosis with erythema nodosum leprosum reactions and recurrent neutrophil leucocytosis in leprosy. Lancet, 2, 572-576.

Missmahl, H. P. (1957). Polarisationsopticher Beitrag zur Kongorotfärbung des Amyloid. Zeitschrift für wissenschaftliche Mikroskopie und für mikroskopische Technik, 63, 133-139.

Muckle, T. J., and Wells, M. (1962). Urticaria, deafness, and amyloidosis: new heredo-familial syndrome. Quarterly Journal of Medicine, 31, 235-248.

Osserman, E. F., Takatsuki, K., and Talal, N. (1964). Multiple myeloma. I. The pathogenesis of 'amyloidosis'. Seminars in Hematology, 1, 3-85.

Pearse, A. G. E. (1969) The cytochemistry and ultrastructure of polypeptide hormone-producing cells of the APUD series and the embryologic, physiologic and pathologic implications of the concept. Journal of Histochemistry and Cytochemistry, 17, 303-313.

Pepys, M. B., Dash, A. C., Munn, E. A., Feinstein, A., Skinner, M., Cohen, A. S., Gewurz, H., Osmand, A. P., and Painter, R. H. (1977). Isolation of amyloid $\mathbf{P}$ component (protein AP) from normal serum as a calcium-dependent binding protein. Lancet, 1, 1029 . 1031.

Pras, M., and Reshef, T. (1972). The acid-soluble fraction of amyloid-a fibril forming protein. Biochimica et biophysica acta, 271, 193-203.

Sheba, C. (1970). Gene-frequencies in Jews. Lancet, 1, 1230-1231.

Sletten, K., Westermark, P., and Natvig, J. B. (1976). Characterization of amyloid fibril proteins from medullary carcinoma of the thyroid. Journal of Experimental Medicine, 143, 993-998.

Tashjian, A. H., Jr., Wolfe, H. J., and Voelkel, E. F. (1974). Human calcitonin. American Journal of Medicine, 56, 840-849.

Vassar, P. S., and Culling, C. F. A. (1959). Fluorescent stains, with special reference to amyloid and connective tissues. Archives of Pathology, 68, 487-498.

Williams, E. D., Brown, C. L., and Doniach, I. (1966). Pathological and clinical findings in a series of 67 cases of medullary carcinoma of the thyroid. Journal of Clinical Pathology, 19, 103-113. 